\title{
Errata Faits de Langues 27
}

\section{Article d'Antoine Lonnet}

Les éléments graphiques ont subi des pertes dans la conversion informatique. On notera :

p. 29 : le grand carré à coins arrondis qui contient les noms de cinq des six langues doit être sous-titré "SAM continental".

p. 28 : carte de la côte sud de l'Arabie, au lieu de al-Qayda, lire al-Gayḍa (avec point au dessus de G et point sous d).

\section{Article de Paolo Marrassini}

p. 221, note 16 : au lieu de "Cela a été dû à une méprise de Christian (191920)", lire "Ceci était dû à une mauvaise interprétation de l'article de Christian $(1919-20)^{\prime \prime}$ 